\title{
Disorder of Androgen Synthesis
}

National Cancer Institute

\section{Source}

National Cancer Institute. Disorder of Androgen Synthesis. NCI Thesaurus. Code C120375.

An enzyme deficiency in the androgen biosynthesis pathway, resulting in the underproduction of one or more androgens by the adrenal glands and/or gonads. 